\title{
UM SISTEMA DE AVALIAÇÃO ATRAVÉS DE VERIFICAÇÕES PARCIALMENTE CUMULATIVAS
}

Jorge Honorio M. Brito *

BRITO, Jorge Honorio M. Um sistema de avaliação através de verificações parcialmente cumulativas. Revista da Faculdade de Odontologia, Porto Alegre, 25:61-5, 1983.

Descritores: Educação odontológica, Graduação - Aprendizagem, Avaliação.

\section{RESUMO}

O autor descreve o sistema de avaliação usado na disciplina de Histologia e Embriologia Bucodentárias do curso de odontologia da UFRGS, no qual o conteúdo programático é avaliado através de cinco verificações escritas, parcialmente cumulativas das cinco unidades que integram o referido conteúdo. Os resultados foram comparados e analisados estatisticamente pelo teste " $t$ " de Student, para um nível de significância de 0,01 . A conclusão é pela validade do método que proporciona uma reaprendizagem, reforçando a retenção de conhecimentos adquiridos na mencionada disciplina.

\section{INTRODUÇÃO}

Os dicionários definem avaliação como "uma determinação de valor". Portanto, indicam que a avaliação constitui um processo de duas partes. A primeira parte da avaliação é a definição do que é de valor ou, em termos mais simples, a identificação dos objetivos ou alvos visados pelo processo educacional. A segunda consiste em julgar se estas metas estão efetivamente sendo atingidas ou, mais realisticamente, a medida em que o estão.

Quando os objetivos de uma disciplina estão definidos, se estabelecem os instrumentos de mensuração capazes de propiciar uma apreciação de "quem aprende. A mensuração é um processo que permite determinar a medida na qual os objetivos estipulados estão sendo alcançados. Assim, um teste objetivo de histologia dá margem à mensuração de quanto de histologia o aluno aprendeu; a compáração com um padrão ou critério pré-determinado proporciona a apreciação de como se conduziu o estudante. O todo pode ser chamado de avaliação, pois abrange determinação de objetivos e apreciação do progresso em sua direção.

MILLER ${ }^{1}$ define avaliação como "um processo contínuo, baseado em cri-

\footnotetext{
* Livre-Docen te e Prof. Adj unto do Departamento de Ciências Morfológicas da UFRGS.
} 
térios específicos desenvolvidos de modo cooperativo, que diz respeito ao comportamento dos alunos e destinado a proporcionar informação sobre seu progresso e o valor dos conteúdos".

A avaliação, para JURACY MARQUES" ${ }^{2}$ "tende a ser uma compreensão progressiva do grau de desenvolvimento pessoal e profissional que o aluno atingiu num determinado momento. Ela deve ser contínua e cumulativa". A mesma autora afirma que "a avaliação deve ser um todo; os procedimentos para realizá-la, como trabalhos individuais, testes e ensaios, pesquisas de grupo, verificações periódicas, colaboração em classe, entrevistas, inquéritos, etc. . ., não são mais do que partes da avaliação".

Existem vários fatores que possivelmente influem na capacidade do aluno reter o que aprende. MEDNICK ${ }^{3}$ relata uma experiência sobre memória realizada por um psicólogo, estabelecendo para seu filho de pouca idade a leitura diária de histórias do Pato Donald e alguns trechos de Sófocles. Seis anos mais tarde o filho, que não se recordava dos trechos, leu-os novamente, junto com outros trechos novos. Constatou-se que foram necessárias 435 repetições para que aprendesse os trechos novos e 317 para aprender os antigos. Este é um exemplo em favor da persistência dos efeitos da aprendizagem, conhecida como traço de memória.

Quando se considera o processo de ensino-aprendizagem, há interesse no destino do comportamento aprendido, através de vários períodos de tempo. Para aferir a memória em laboratório, os psicólogos usam três métodos básicos: a recordação, através da qual o aluno diz o que aprendeu; o reconhecimento que é uma questão de discriminação do que foi aprendido em face de outros conteúdos; e a reaprendizagem que é uma medida de retenção aferida após um reestudo realizado com algum intervalo de tempo.

Estes aspectos, sucintamente referidos, levaram o autor a adotar na disciplina de Histologia e Embriologia Bucodentárias do curso de odontologia da UFRGS, um sistema de cinco verificações escritas parcialmente cumulativas do conteúdo programático da disciplina, visando medir a reaprendizagem daí decorrente. Este trabalho relata a análise dos resultados obtidos.

\section{MATERIAL E MÉTODO}

A experiência foi realizada com 72 alunos matriculados na disciplina de Histologia e Embriologia Bucodentárias, do curso de odontologia da UFRGS, durante o segundo semestre letivo de 1982.

Definiu-se um sistema de avaliação composto de cinco verificações escritas e duas práticas, abrangendo o conteúdo programático da seguinte forma:

verificação escrita 1

- Tecidos dentários (unidade 1)

verificação escrita 2

- Periodonto (unidade 2)

- Tecidos dentários (unidade 1)

Verificação escrita 3

- Embriologia dentária (unidade 3)

- Periodonto (unidade 2)

Verificação escrita 4

- Histologia da cavidade oral (unidade 4). Embriologia dentária (unidade 3)

Verificação escrita 5

- Embriologia geral e da cavidade bucal (unidade 5)

Verificação prática 1

- unidades 1 e 2 
Verificação prática 2

- unidades 1 a 5

Como se verifica, a unidade 1 foi aferida três vezes, as unidades 2 e 3 duas vezes e as unidades 4 e 5 apenas uma vez. O sistema estabelecido obrigava o estudante com grau inferior a seis, em qualquer unidade, à recuperação. Esta recuperação podia ser alcançada na repetição, desde que obtido o grau 8. Ao final do semestre foi oferecida uma nova oportunidade de recuperação aos que permaneceram com grau inferior a seis em qualquer uma ou todas as unidades.

O conceito final foi obtido através da média aritmética de todos os graus obtidos, mais um conceito parcial atribuído a cada aluno pela assiduidade, pontualidade e interesse demonstrados nas atividades programadas. A conversão dos graus numéricos em conceito final obedeceu o seguinte critério:

$\geqslant 9.0$ correspondeu ao conceito $A$

$=7.5$ até $<9.0$ correspondeu ao conceito B

$=6.0$ até $<7.5$ correspondeu ao conceito $\mathrm{C}$

\section{$<6.0$ correspondeu ao conceito D} (reprovação)

As verificações escritas foram elaboradas sob a forma de testes objetivos de diversos tipos e questões dissertativas, abrangendo a totalidade dos conteúdos. As verificações práticas foram realizadas usando vinte microscópios de campo fixo, com perguntas colocadas ao lado de cada um, respondidas por escrito num tempo determinado de um minuto e meio. Nas verificações repetidas (unidades 1, 2 e 3) foram usadas as mesmas provas, cabendo esclarecer que as verificações são comentadas mas não devolvidas aos estudantes.
A análise estatística dos resultados restringiu-se às verificações que envolveram as unidades 1, 2 e 3, utilizando testes de significância pela distribuição " $t$ " de Student, com grau de liberdade igual a 141, para um nível de significância de 0.01 .4

\section{ANÁLISE E DISCUSSÃO DOS RESULTADOS OBTIDOS}

Os dados obtidos estão expressos no quadro seguinte: 


\begin{tabular}{l|c|c|c|c|c|c|c}
\hline & \multicolumn{3}{|c|}{ unidade 1 } & \multicolumn{2}{c|}{ unidade 2 } & \multicolumn{2}{c}{ unidade 3 } \\
\cline { 2 - 8 } & 19 & $2 a$ & $3 a$ & $1 !$ & 29 & 19 & 2 a \\
\hline média & 7.54 & 8.10 & 8.39 & 7.93 & 7.77 & 7.95 & 8.54 \\
\hline desvio padrão & 0.82 & 0.95 & 1.14 & 1.27 & 1.14 & 1.40 & 1.04 \\
\hline
\end{tabular}

População $=72$ alunos

grau de liberdade $=141$

teste $\mathbf{t}$ de Student (0.01)

Observa-se que nas verificações referentes à unidade 1 (tecidos dentários) a média inicial de 7.54 elevou-se para 8.10 na segunda e 8.39 na terceira. Comparando a primeira com a segunda verificações, a elevação da média foi significante estatisticamente, o que não ocorreu entre a segunda e terceira, mesmo considerando que a última média foi mais alta. Cs resultados demonstraram que a retenção de conhecimentos pela reaprendizagem foi manifestamente positiva.

Nos resultados relacionados à unidade 2 (periodonto) não houve significância estatística, mas a análise também não permitiu inferir que a retenção foi menor, como se poderia depreender da simples observação das médias obtidas nesta unidade.

A análise estatística das médias correspondentes à unidade 3 (embriologia dentária) apresentou significância estatística, o que permite supor o aumento da retenção de conhecimentos.

Os resultados obtidos parecem demonstrar que o sistema de verificações com conteúdos parcialmente cumulativos reforça a aprendizagem, já que a retenção de conhecimentos, analisada conjuntamente, foi significante em duas oportunidades, e nas outras duas a média foi mais elevada em uma e decresceu na outra, sendo que a análise estatística não permitiu considerar esta diminuição como redução na retenção de conhecimentos.

\section{CONCLUSÃO}

O sistema de avaliação adotado pela disciplina de Histologia e Embriologia Bucodentárias, usando verificações escritas parcialmente cumulativas, proporcionou um reforço de aprendizagem, o que deverá elevar os níveis de recordação e reconhecimento dos alunos.

A experiência comprovou a validade do método empregado, permitindo recomendá-lo no ensino de disciplinas cujo conteúdo programático é desenvolvido através de comunicações, estudo individual de textos e atividades de observação microscópica e desenho dos campos estudados.

\section{SUMMARY}

The author describes the grading system used in the course of oral histology and embriology of the dentistry graduation at Federal University of Rio Grande do Sul, in wich the programmatic content is appraised through five partially cumulative written examinations concerning the five units that integrate 
the refered content. The results were compared and analyzed statistically by the Student's t test, for a level of significance of 0.01 . The conclusion is for the validity of the method, wich provides a relearning, re-enforcing the retention of the acquired knowledge in the mentioned discipline.

\section{REFERÊNCIAS BIBLIOGRÁFICAS}

1. MILLER, G.E. - Ensino e aprendizagem nas escolas médicas. Trad. de Maria Helena Caldas de Oliveira. São Paulo, Ed. Nacional, 1967.

2. MARQUES, Juracy C. - Ensinar não é transmitir. 2.ed. rev. e amp. Porto Alegre, Globo, 1974.

3. MEDNICK, S.A. - Aprendizagem. Trad. de Alvaro Cabral. Rio de Janeiro, Zahar, 1967.

4. HOEL, Paul G. - Estatística elementar. Rio de Janeiro, Fundo de Cultura, 1963. 